Predicting Pornography Use Over Time:

Does Self-Reported “Addiction” Matter?

Joshua B. Grubbs

Bowling Green State University

Joshua A. Wilt \& Julie J. Exline

Case Western Reserve University

Kenneth I. Pargament

Bowling Green State University

Author Indexed Pre-Print, citation:

Grubbs, J. B., Wilt, J. A., Exline, J. J., \& Pargament, K. I. (2018). Predicting pornography use over time: Does self-reported "addiction” matter? Addictive Behaviors, 82, 57-64. https://doi.org/10.1016/j.addbeh.2018.02.028

Correspondence concerning this article should be addressed to Joshua B. Grubbs, Ph.D., Department of Psychology, Bowling Green State University, Bowling Green, OH, 43403. Email: GrubbsJ@BGSU.edu 


\title{
Predicting Pornography Use Over Time: Does Self-Reported “Addiction” Matter?
}

\begin{abstract}
In recent years, several works have reported on perceived addiction to internet pornography, or the potential for some individuals to label their own use of pornography as compulsive or out of control. Such works have consistently found that perceived addiction is related to concerning outcomes such as psychological distress, relational distress, and other addictive behaviors. However, very little work has specifically examined whether or not perceived addiction is actually related to increased use of pornography, cross-sectionally or over time. The present work sought to address this deficit in the literature. Using two longitudinal samples (Sample 1, Baseline $N=3,988$; Sample 2, Baseline $N=1,047$ ), a variety of factors (e.g., male gender, lower religiousness, and lower self-control) were found to predict any use of pornography. Among those that acknowledged use (Sample 1, Baseline $N=1,352$; Sample 2, Baseline $N=793$ ), perceived addiction to pornography consistently predicted greater average daily use of pornography. At subsequent longitudinal follow-ups (Sample 1, Baseline $N=265$; Sample 2, One Month Later, $N=410$, One Year Later, $N=360$ ), only male gender and baseline average pornography use consistently predicted future use. These findings suggest that perceived addiction to pornography is associated with concurrent use of pornography, but does not appear to predict use over time, suggesting that perceived addiction may not always be an accurate indicator of behavior or addiction.
\end{abstract}

Keywords: Pornography; Technology; Addiction; Longitudinal; Perception; Religion.

\section{Introduction}

In developed countries, the majority of adults with internet access have seen internet pornography (Price, Patterson, Regnerus, \& Walley, 2016; Rissel et al., 2017; Wright, 2012, 2013). Moreover, in nationally representative studies of adults in the U.S., up to $46 \%$ of men and $16 \%$ of women report intentionally consuming internet pornography within the past week (Regnerus, Gordon, \& Price, 2016). Together, these findings suggest that internet pornography use $^{1}$ (hereafter: IPU) is a frequent behavior.

However, this use is also controversial, with wide ranging debates about its effects and potentials for harm (for reviews, see: Duffy, Dawson, \& das Nair, 2016; Rasmussen, 2016; Short, Black, Smith, Wetterneck, \& Wells, 2011; Short, Wetterneck, Bistricky, Shutter, \& Chase, 2016).

\footnotetext{
${ }^{1}$ Abbreviations used: IPU = Internet Pornography Use; PAtIP $=$ Perceived Addiction to Internet Pornography.
}

Since the advent of the internet and its consequent use as a medium for the sharing of sexually explicit materials, there have been warnings decrying the addictive nature of internet pornography (Al Cooper, 1998). Although many scholars urged caution before assuming these dangers (e.g., Barak, Fisher, Belfry, \& Lashambe, 1999; Fisher \& Barak, 2001), the notion of internet pornography addiction quickly took hold in academic literature (Al Cooper, Delmonico, \& Burg, 2000) and popular awareness (Boulton, 2008). At present, internet pornography addiction is the subject of dozens of self-help books (Foubert, 2016; Struthers, 2009; Wilson, 2014), online communities ("Reboot Nation," 2017; "Your Brain On Porn," 2017), and support groups ("NoFap.com," 2017). Additionally, there is some evidence that problems related to IPU and purported addiction are also regularly encountered 
by mental health professionals in their clientele (Gola, Lewczuk, \& Skorko, 2016; Kalman, 2008; Kraus, Martino, \& Potenza, 2016; Mitchell, Becker-Blease, \& Finkelhor, 2005; Short et al., 2016; Twohig \& Crosby, 2010). Despite this popularity, scholarly debates about the accuracy and utility of such a construct continue into the present (Clarkson \& Kopaczewski, 2013; Ley, Prause, \& Finn, 2014).

Alongside these debates about the veracity and utility of a pornography addiction diagnosis, there has been increasing attention paid to perceived addiction to internet pornography (BlaisLecours, Vaillancourt-Morel, Sabourin, \& Godbout, 2016; Duffy et al., 2016; Grubbs, Stauner, Exline, Pargament, \& Lindberg, 2015; Grubbs, Volk, Exline, \& Pargament, 2015; Grubbs, Wilt, Exline, Pargament, \& Kraus, 2017; Leonhardt, Willoughby, \& Young-Petersen, 2017). Perceived addiction to internet pornography (hereafter: PAtIP) refers to the propensity of individuals to identify as having struggles with IPU, such as perceived compulsivity in use, regardless of whether or not their behaviors are objectively dysregulated ${ }^{2}$ (Grubbs, Exline, Pargament, Hook, \& Carlisle, 2015). Although PAtIP is clearly related to IPU cross-sectionally (Grubbs, Exline, et al., 2015; Grubbs, Wilt, et al., 2017; Leonhardt et al., 2017), a number of studies have consistently found that moral incongruence about IPU (i.e., using pornography although one personally disapproves of pornography) tends to be a better predictor of PAtIP than actual IPU (Fernandez, Tee, \& Fernandez, 2017; Grubbs,

${ }^{2}$ Of note, the research community is yet unclear on the exact definition of objective dysregulation as it applies to IPU. For example, early works on the topic of cybersex addiction viewed objective dysregulation as greater than 11 hours per week (Alvin Cooper, Scherer, Boies, \& Gordon, 1999), more recent works have noted that such a definition is not universally agreed upon, while also acknowledging that use exceeding 13 hours a week is likely clinically distinct from use that may be less than 4 hours per week (Kraus, Voon, \& Potenza, 2016). In either case, as the focus of the present work
Wilt, et al., 2017; Volk, Thomas, Sosin, Jacob, \& Moen, 2016). In short, PAtIP seems to be more than just an indicator of behavior and may also be an indicator of personal feelings of guilt or distress about IPU. Even so, PAtIP can be a pressing clinical concern.

PAtIP is linked to various forms of psychological distress such as anxiety and depression (Grubbs, Volk, et al., 2015), spiritual struggles such as anger toward God and feelings of moral failure, lower self-esteem (Wilt, Cooper, Grubbs, Exline, \& Pargament, 2016), relational difficulties (Leonhardt et al., 2017), alcohol use (Morelli, Bianchi, Baiocco, Pezzuti, \& Chirumbolo, 2017), and diminished sexual satisfaction (Blais-Lecours et al., 2016).

Additionally, over time, PAtIP uniquely predicts psychological distress (Grubbs, Stauner, et al., 2015) and religious and spiritual difficulties (Grubbs, Exline, Pargament, Volk, \& Lindberg, 2017). Finally, feelings of addiction to pornography — but not IPU itself — are also related to treatment seeking behaviors for problems associated with IPU (Gola et al., 2016).

In sum, a compelling body of literature suggests that PAtIP is associated with a wide range of concerning mental health and social outcomes. However, as of yet, there has been virtually no work examining how PAtIP might actually predict IPU itself over time. Whereas perceived addiction to some substances (e.g., nicotine) is known to predict engagement in addictive behaviors (Eiser, Pligt, Raw, \& Sutton, 1985; Okoli, Richardson, Ratner, \& Johnson, 2009), no such data currently

was on predicting use at all (regardless of whether or not such behavior is dysregulated), we did not seek to define this term for the population at hand. Furthermore, in prior studies of perceived addiction (Grubbs, Exline, Pargament, Hook, \& Carlisle, 2015; Grubbs, Volk, Exline, \& Pargament, 2015; Grubbs, Wilt, Exline, Pargament, \& Kraus, 2017; Leonhardt, Willoughby, \& Young-Petersen, 2017) and within the present work, average reported use has often fallen well below an average of 11-13 hours per week, again suggesting a distinction between perceived addiction and excessive behaviors. 
exist for pornography. If PAtIP is a consistent indicator of actual problems with IPU, then we might expect to find that it would predict greater IPU both concurrently (as has been found in prior literature; Grubbs, Exline, et al., 2015; Leonhardt et al., 2017) and over time (which is yet untested). In other words, if self-reported feelings of addiction are actually reflective of dysregulation, then we might expect to find that PAtIP would be associated with increasing patterns of use over time (e.g., as is seen with substance use, Eiser et al., 1985; Okoli et al., 2009) or to uniquely predict use over time, above and beyond other explanatory variables. In contrast, if it is not simply an accurate indicator of dysregulation but also expression of distress or guilt over use, then such relationships might not emerge. To this end, the purpose of the present work was to examine what factors are related to IPU both concurrently and over time, with a specific interest in the role of PAtIP in contributing to such use.

\subsection{The Present Study}

Given prior literature linking self-reported IPU to lower levels of religiousness (Perry, 2015, 2017; Rasmussen \& Bierman, 2016; Wright, 2013), greater levels of loneliness (Yoder, Virden III, \& Amin, 2005), lower self-control (Grubbs, Volk, et al., 2015; Grubbs, Wilt, et al., 2017), and greater levels of PAtIP (Grubbs, Exline, et al., 2017; Grubbs, Volk, et al., 2015; Leonhardt et al., 2017), we included these variables as predictors of IPU in analyses. We also included measures of moral disapproval of IPU, as prior works (Grubbs, Exline, et al., 2015; Volk et al., 2016) have linked moral disapproval to PAtIP, but none have examined how moral disapproval might predict IPU. Additionally, we controlled for socially desirable responding in all analyses, as socially desirable responding does appear to be associated with lower reported use of pornography in some samples (Rasmussen, Grubbs, Pargament, \& Exline, 2017). We examined the following hypotheses:
1. We expected to find that crosssectionally, religiousness (-), loneliness $(+)$, self-control (-), and socially-desirable responding (-) would be associated with greater likelihood of reporting any IPU at all. PAtIP was not included as a predictor in this dichotomous prediction (e.g., any use at all vs. no use at all), as only participants who acknowledged use were asked about feelings of PAtIP.

2. Among those who did acknowledge IPU, we expected to find that self-control (-), loneliness $(+)$, socially-desirable responding $(-)$, religiousness (-), moral disapproval of IPU (-), and PAtIP $(+)$ to be cross-sectionally associated with average daily IPU.

3. Among those who acknowledged IPU at baseline, we expected to find that self-control (-), loneliness $(+)$, socially-desirable responding $(-)$, religiousness (-), moral disapproval of IPU (-), and PAtIP

$(+)$ to be associated both acknowledging any IPU over time and with average daily IPU over time.

This work seeks to build upon past work by specifically testing whether or not PAtIP actually predicts behavior over time. As this work represents further analysis of data previously described in the literature (Grubbs, Stauner, et al., 2015; Grubbs, Wilt, et al., 2017), the hypotheses for these studies were generated prior to analysis, but not sui generis with regards to the data. Although we did not predict these findings based on prior knowledge of this specific data (e.g., Hypothesizing After Results are Known; (Kerr, 1998; Spellman, Gilbert, \& Corker, 2017), certain aspects of the following work have been indirectly examined in prior studies. Chiefly, the role of IPU 
(average daily use) in predicting feelings of PAtIP was reported in a previous manuscript (Grubbs, Wilt, et al., 2017). However, the reverse prediction (i.e., PAtIP predicting IPU itself), which is the primary concern of the present work, was not considered in prior works.

2. Materials and Methods

\subsection{Participants and Procedure}

2.1.1 Sample 1. Participants were undergraduates at three universities in the U.S. ( $N$ $=3,988 ; 35.2 \%$ men), a mid-sized private University in the Midwest, a large public university in the Midwest, and a mid-sized private, religiously affiliated (Christian) university in the Southwest. Participants were recruited from introductory psychology classes over the course of 8 semesters.

Participants were primarily

White/Caucasian (69.2\%), followed by Black/African-American (10.6\%), Latino/a (6.1\%), Asian/Pacific-Islander (16.8\%), American Indian or Alaska Native (1.9\%), middle eastern (1.4\%), and "other" or "prefer not to say" $(2.2 \%)$. Participants primarily identified as Christian (66.0\%), followed by Atheist/Agnostic (12.3\%), "none" (6.9\%), "other" (3.4\%), Jewish (1.4\%), Buddhist (0.7\%), Muslim (0.5\%), and Hindu $(0.8 \%)$. Participants reported identifying primarily as heterosexual (90.1\%), bisexual (4.4\%), lesbian/gay (3.3\%), asexual $(0.3 \%)$, and "other" or "prefer not to say" (1.7\%).

Beyond initial analyses addressing our first hypothesis (i.e., who acknowledges any pornography at all?), we limited our sample only to those who acknowledged viewing pornography at least once in the 6 months prior to our survey. This led to a revised sample size of 1,352 (67.7\% men).

Participants who 1) were in their first year of college at baseline, 2) endorsed IPU at baseline, and 3) also agreed to be contacted again about future research were emailed one year later about the opportunity to participate in a follow-up survey. For this follow-up, we only focused on those who acknowledged IPU at Time 1, as they were the only participants to complete all measures at Time 1 (e.g., measures of PAtIP, average daily use, and moral disapproval). Of the 632 contacted, 265 (55.1\% men; 42.5\% response rate; Minterval= 333.2 days, $\mathrm{SD}=25.3$ ) completed the second survey. MANOVA revealed no multivariate differences on variables of key interest (e.g., IPU, PAtIP, religiousness) between those who completed the follow-up and those who did not. Additionally, only those who acknowledged IPU within the past month were asked about average daily use (see below), meaning that, for some longitudinal analyses (logistic regressions), the full sample of 265 participants were included, whereas for other analyses (multiple regressions), the sample was limited to the 146 who acknowledged some IPU at time 2.

\subsubsection{Sample 2. Participants for our} second sample were adults in the United States recruited using Amazon's Mechanical Turk (MTurk) workforce database (Total $N=1,047$, $39.6 \%$ men). MTurk is popular in psychosocial research and is often suitable for a wide range of behavioral, psychological, and even medical studies (Buhrmester, Kwang, \& Gosling, 2011; Chandler \& Shapiro, 2016; Shapiro, Chandler, \& Mueller, 2013).

Participants were primarily white/Caucasian (79.3\%), followed by African American (10.8\%), Latino/a (7.1\%), Asian/PacificIslander (6.3\%), American Indian or Alaska Native (3.8\%), and "other" or "prefer not to say" (1.1\%). Participants predominantly identified as heterosexual $(83.9 \%)$, followed by bisexual $(9.3 \%)$, gay or lesbian $(3.5 \%)$, pansexual $(1.5 \%)$, asexual $(0.5 \%)$, and other/prefer-not-to-say (1.2\%). Regarding religious affiliations, participants most often reported identifying as Christian (39.7\%), followed by Atheist/Agnostic (36.4\%), "none" (15.8\%), "other" (3.4\%), Jewish (1.9\%), Buddhist (1.5\%), Muslim (0.6\%), and Hindu (0.4\%).

Beyond initial analyses addressing our first hypothesis (i.e., who acknowledges any pornography at all?), we limited our sample only to 
those who acknowledged viewing pornography at least once in the 6 months prior to our survey. This led to a revised sample size of 793 (48.8\% men).

At one month after the initial survey and one year after the initial survey, all participants who had 1) completed the study at baseline, 2) reported IPU at baseline (i.e., completed all pornography measures) and 3) agreed to be contacted again were notified through MTurk about the follow-up research opportunity. Among participants, 672 met these criteria. Of those contacted at one month, 410 completed the followup survey ( $52 \%$ men, $60.9 \%$ response rate; $M_{\text {interval }}$ $=30.7$ days, $S D=1.6)$. As was the case with Sample 1, some analyses were limited to those who acknowledged IPU within one month of our one-month follow-up $(N=199)$. At one year, 360 completed follow-up materials (52\% men; 54\% response rate; $M_{\text {interval }}=363.3$ days, $\mathrm{SD}=5.0$ ). Again, some analyses were limited to those who acknowledged IPU within one month of our oneyear follow-up ( $N=176)$.

Due to limited sample size (i.e., limited statistical power) of those who completed all measures at all time points $(n=107)$ we chose to analyze the follow-up data points independently (e.g., baseline predicting results at one month and predicting results at one-year), rather than multiple-time-point analyses (e.g., latent growth curve modeling).

\subsection{Measures}

2.2.1 Pornography use. At baseline, IPU was broadly assessed in two ways. In the total sample for both samples, we asked all participants whether they had intentionally viewed pornography at all in their life time. Furthermore, among those who indicated that they had viewed pornography intentionally in the past, we asked them to report their average daily IPU in hours.

At follow-up time-points (one year in Sample 1; one month and one year in Sample 2), we again assessed IPU in two ways: 1) we asked all participants whether or not they had viewed pornography in the past month and 2) among those who reported use, we asked them to report their average daily use in hours.

At baseline and all follow-up points, participants reported their average daily IPU on a scale of 0 to 12 hours daily (in intervals of 0.1 hours).

\subsubsection{Perceived addiction to internet} pornography. We included the Cyber-

Pornography Use Inventory-9 (CPUI-9; (Grubbs, Volk, et al., 2015). This 9-item measure assesses indicators of PAtIP on three, 3-item subscales: Perceived Compulsivity (e.g., "Even when I don't want to view pornography online, I feel drawn to it."), Emotional Distress (e.g., "I feel depressed after viewing pornography online."), and Access Efforts (e.g., I have put off important priorities to view pornography."). Participants rated their agreement (i.e., "How well do the following items describe you?") with these items on a scale of 1 (not at all) to 7 (extremely).

\subsubsection{Moral disapproval of IPU. To} assess moral disapproval, we used items reported in prior studies (Grubbs, Exline, et al., 2015; Grubbs, Wilt, et al., 2017). These four items include two non-religiously worded items (e.g., "Viewing pornography online would trouble my conscience") and two more religiously worded items (e.g., "I believe that viewing pornography online is a sin"). Participants rated their agreement with statements on a scale of 1 (not at all) to 7 (extremely). As prior analyses on the topic (Grubbs, Exline, et al., 2015) did not find any meaningful statistical differences between using all four items or just the two non-religious items, our analyses made use of all four items.

2.2.4 Religiousness. Religious belief salience was assessed using a modified version of an existing scale (Blaine \& Crocker, 1995). This 5item scale asks participants to rate their agreement with statements such as, "Being a religious/spiritual person is important to me" on a scale of 0 (strongly disagree) to 10 (strongly agree). 
Religious participation was assessed using a modified version of an existing measure (Exline, Yali, \& Sanderson, 2000). This scale asks participants how frequently they engage in certain religious behaviors (e.g., "Over the past week, how often have you prayed?" or "Over the past week, how often have you attended religious services?") on a scale of 1 (not at all) to 5 (multiple times per day).

Consistent with prior works (Grubbs, Exline, et al., 2015; Grubbs, Wilt, et al., 2017), we did not differentiate between these two measures, instead standardizing items and condensing them into a single index.

2.2.5 Individual Differences. We included the Brief Self Control Scale (Tangney, Baumeister, \& Boone, 2004). This scale asks participants to indicate agreement with statements (e.g., "I am good at resisting temptation") on a scale of 1 (not at all like me) to 5 (very much like $m e)$.

We also included the Three Item Loneliness Scale (Hughes, Waite, Hawkley, \& Cacioppo, 2004). This measure requires participants to rate the frequency with which they feel lonely (e.g., "How often do you feel you lack companionship?") on a scale of 1 (hardly ever) to 3 (often).

Finally, we included the brief MarlowCrowne Scale of Socially Desirable Responding (Reynolds, 1982). This scale requires participants to answer either "True" or "False" to a series of statements (e.g., "It is sometimes hard for me to go on with my work if I am not encouraged").

Socially desirable responses are assigned a value of 1 ; other responses are assigned a value of 0 . Responses are summed.

\subsection{Planned Analyses}

We conducted post-hoc analyses of existing data: ergo, sample size was already determined. As such, we relied on post-hoc tests of obtained power (as opposed to a priori power estimation). Power analyses were conducted using the pwr package (Champely, 2009) for R statistical software with an alpha level of .05 and an observed power of .95. For baseline analyses involving all participants (both pornography users and nonusers) in both samples, we found that we had sufficient power to detect even very small effects in regression models with up to 9 predictor variables (Sample 1, $N=3,988, f^{2}=.006$; Sample 2, $\left.N=1,047, f^{2}=.023\right)$. For analyses of average daily use among users at baseline, we found we again had sufficient power to detect even very small effects with regression analyses with up to 9 predictor variables (Sample $1, N=1,507, f^{2}=.015$; Sample 2, $N=782, f^{2}=.03$ ). For longitudinal analyses, power analyses revealed a range of reliable effect sizes (Sample 1, 1-year: Total $N=265, f^{2}=.091 ; N$ of Users $=146, f^{2}=.171$; Sample 2, 1-month: Total $N=410, f^{2}=.059 ; N$ of Users $=199, f^{2}=.123$; Sample 2, 1-year: Total $N=360, f^{2}=.067 ;$ of Users $=176, f^{2}=.142$ ).

Cross-sectionally, we used logistic regressions to determine what factors were associated with any reported IPU. Among reported users, we reported Pearson correlations to demonstrate the associations between baseline variables. Additionally, we used multiple regressions to predict average daily IPU, with gender, religiousness, self-control, loneliness, selfesteem, and dimensions of PAtIP as predictor variables.

Longitudinally, we used logistic regressions to predict reported IPU over time. Additionally, we used multiple regressions to predict average daily IPU over time, with gender, religiousness, self-control, loneliness, self-esteem, baseline IPU, and dimensions of PAtIP as predictor variables.

Throughout analyses, Holm-adjusted test statistics were used. The Holm adjustment is a sequentially rejective adaptation of the Bonferroni correction which drastically reduces the Type-1 error rate (Revelle, 2014). In conjunction with our power criteria (e.g., alpha $=.05$, power $=.95$ ), these corrections drastically reduce the likelihood of erroneous interpretation of Type 1 errors. 


\section{Results}

\subsection{Cross-Sectional Analyses}

In both samples, logistic regression results indicated that self-control and self-reported religiousness predicted substantially decreased odds of reporting IPU, while male gender predicted substantially increased odds (see Table 2). In Sample 1, loneliness predicted increased odds of IPU; however, this finding was not present in Sample 2.

Among those who acknowledged use of pornography, in both samples, daily IPU correlated positively with PAtIP, with specific associations with cognitive (perceived compulsivity) and behavioral (access efforts) components of PAtIP most apparent (see Table 3). In Sample 2, average daily use inversely correlated with self-control, though this finding was not evident in Sample 1.

In both samples, both cognitive and behavioral aspects of PAtIP predicted greater reported daily IPU in multiple regressions (see Table 4). In Sample 1, moral disapproval of IPU negatively predicted IPU, as did emotional distress regarding IPU. However, these findings were not replicated in Sample 2. Additionally, only in Sample 2, male gender identification positively predicted average daily use.

\subsection{Longitudinal Analyses}

In all three logistic regression analyses (Sample 1, 1 year; Sample 2, 1 month and 1 year), male gender predicted self-report of IPU over time (see Table 5). In Sample 1, but not in Sample 2 (at either time point), cognitive aspects of PAtIP (perceived compulsivity) predicted increased odds of self-reported IPU. In Sample 2, average daily IPU predicted greater likelihood of reported IPU over a one month time period. In Sample 2, over a one year time period, self-control predicted diminished odds of self-reported IPU, and average daily IPU predicted increased odds.

Across all three simultaneous regression analyses, the only consistent predictor of average daily IPU over time was average daily IPU at baseline. In Sample 2, over a one year time period, both loneliness and behavioral components of PAtIP (access efforts) also predicted greater average IPU over time. However, these findings were not evident in any of the other analyses.

\section{Discussion}

At the outset of this work, we sought to examine how various individual differences, particularly PAtIP, might predict IPU both concurrently over time. Across two moderatelysized samples involving both undergraduates and web-using adults, various factors were consistently associated with having reported any history of IPU. Specifically, consistent with prior literature, male gender was associated with greater reports of use and both self-control and religiousness were associated with lesser reports. Among users (i.e., those who reported any history of use), the only consistent, cross-sectional predictors of average daily use were elements of PAtIP: specifically, feelings of perceived compulsivity and perceived effort to obtain pornography. Over time, male gender was the only consistent predictor of reported IPU (any use within the past month). Regarding average daily use over time, in both samples, the only consistent predictor of such use was average daily use at baseline.

\subsection{Implications}

Whereas factors such as personality (e.g., self-control) and religiousness may predict either 1) lifetime IPU or 2) overall willingness to report lifetime IPU, among pornography users themselves, individual difference variables seem to be less consistent predictors, particularly over time. Ergo, personality may not be a key predictor of amount of IPU among pornography users. Certainly, individual differences might predict individuals who transition from never-users to users, but, among those who actually report using pornography at baseline, individual difference variables seem less useful in predicting use. Crosssectionally, there is certainly evidence that PAtIP is related to more IPU, but over time, such findings did not persist. These findings strongly suggest that IPU is not well-predicted by PAtIP or any of its 
components. Collectively, these findings suggest that PAtIP and IPU itself likely exist on somewhat distinct spectra. Although there are certainly links between the two domains, particularly in concurrent research, there is a paucity of evidence suggesting that PAtIP would lead to more use or, given past literature (26), that more use would lead to greater levels of PAtIP. In short, whereas PAtIP certainly does impact behavior in other addictions (Eiser et al., 1985; e.g., substance use, Okoli et al., 2009) the same relationships are not apparent in relation to IPU, suggesting that self-reported pornography addiction is likely more complex and nuanced than other forms of behavioral addiction or dysregulation (e.g., gambling, substance-use).

Consistent with prior works on this topic, the conclusions of the present work bear implications for both research and clinical work. With regards to research, future work examining self-reported experiences of addiction to pornography need to also carefully control for actual levels of use. Although there is no clear definition of "objective dysregulation" as it relates to IPU, there is a need for future research to document the relationships between actual behaviors and self-reported perceptions of those behaviors. Clinically, the present work adds to a growing line of research demonstrating that IPU itself is often unrelated to treatment-seeking or identification as having problematic IPU patterns (Gola et al., 2016; Kraus, Martino, et al., 2016). There is now evidence in various literatures that IPU does not predict PAtIP over time (Grubbs, Wilt, et al., 2017), that IPU does not predict treatment seeking (Gola et al., 2016; Kraus, Martino, et al., 2016), and, with the present study, that PAtIP does not predict use over time. This suggests that, in clinical settings, addressing objective use may not be the most salient clinical priority. Although use may be a focus of treatment, the present work adds to the body of literature suggesting that other factors, such as perceived disruption and consequences (Gola et al., 2016), moral incongruence (Grubbs \& Perry, 2018), or generalized distress (Grubbs, Stauner, et al., 2015), may need to be the primary focus of treatment for problematic IPU.

\subsection{Limitations and Future Directions}

Our work relied on self-report measures, the limitations of which are well-known (Chan, 2009). Additionally, we only tested these constructs in community, rather than clinical, samples. Although PAtIP may not predict greater IPU over time in the community, among a clinical sample, whose symptoms are likely more severe, such relationships may differ. For the purpose of the present study, we did not actually define objective dysregulation either to our participants or for our own analyses, as the focus of the present work was on use itself, not whether or not such use was actually dysregulated. Future work would be well-served to examine how PAtIP might relate to an objective standard of dysregulation, should such a standard be developed. Although we have inferred from our findings that the present results indicate that PAtIP is relatively unassociated with dysregulation, without clear, consensus-based definitions of what such dysregulation might be, our inferences are speculative and tentative, rather than conclusive. Also, the present work did not examine whether or not the relationships between PAtIP and IPU might be reciprocal in nature; that is, we did not test whether growth in one might correspond to growth in the other. This is a direction that future research should strongly consider. Finally, these samples were derived exclusively from the U.S., which hampers generalizability to other cultural contexts.

\section{Conclusions}

IPU remains a common and controversial topic, with continued focus in empirical literature on problems that might be associated with such use. Across two longitudinal samples, we examined how PAtIP might actual relate to IPU behaviors. Consistently, in both samples, PAtIP was associated with greater use of pornography cross-sectionally, but it demonstrated virtually no relationships with IPU over time. Collectively, 
these findings suggest that feelings of addiction to pornography might not be useful indicators of future behavior patterns or IPU.

\section{Acknowledgements}

We gratefully acknowledge the support of the John Templeton Foundation (Grant \#s 36094 \& 59916) in funding this project. The content of this manuscript does not necessarily reflect the views of the funding agencies and reflects the views of the authors.

\section{References}

Barak, A., Fisher, W., Belfry, S., \& Lashambe, D. (1999). Sex, guys, and cyberspace. Journal of Psychology \& Human Sexuality, 11, 6391. https://doi.org/10.1300/J056v11n01_04

Blaine, B., \& Crocker, J. (1995). Religiousness, race, and psychological well-being: Exploring social psychological mediators. Personality and Social Psychology Bulletin, 21, 1031-1041.

Blais-Lecours, S., Vaillancourt-Morel, M.-P., Sabourin, S., \& Godbout, N. (2016). Cyberpornography: Time use, perceived addiction, sexual functioning, and sexual satisfaction. Cyberpsychology, Behavior, and Social Networking, 19, 649-655. https://doi.org/10.1089/cyber.2016.0364

Boulton, C. (2008). Porn and me(n): Sexual morality, objectification, and religion at the wheelock anti-pornography conference. The Communication Review, 11, 247-273. https://doi.org/10.1080/107144208023065 44

Buhrmester, M., Kwang, T., \& Gosling, S. D. (2011). Amazon's Mechanical Turk: A new source of inexpensive, yet highquality, data? Perspectives on Psychological Science, 6, 3-5.

Champely, S. (2009). pwr: Basic functions for power analysis. $\mathrm{R}$ package version 1.1. 1. The R Foundation: Vienna.
Chan, D. (2009). So why ask me? Are self-report data really that bad. Statistical and Methodological Myths and Urban Legends: Doctrine, Verity and Fable in the Organizational and Social Sciences, 309336.

Chandler, J., \& Shapiro, D. (2016). Conducting clinical research using crowdsourced convenience samples. Annual Review of Clinical Psychology, 12.

Clarkson, J., \& Kopaczewski, S. (2013). Pornography addiction and the medicalization of free speech. Journal of Communication Inquiry, 37, 128-148. https://doi.org/10.1177/019685991348233 0

Cooper, A. (1998). Sexuality and the Internet: Surfing into the new millennium. CyberPsychology \& Behavior, 1, 187-193. https://doi.org/10.1089/cpb.1998.1.187

Cooper, A., Delmonico, D. L., \& Burg, R. (2000). Cybersex users, abusers, and compulsives: New findings and implications. Sexual Addiction \& Compulsivity, 7, 5-29. https://doi.org/10.1080/107201600084002 05

Cooper, A., Scherer, C. R., Boies, S. C., \& Gordon, B. L. (1999). Sexuality on the Internet: From sexual exploration to pathological expression. Professional Psychology: Research and Practice, 30, 154.

Duffy, A., Dawson, D. L., \& das Nair, R. (2016).

Pornography addiction in adults: A systematic review of definitions and reported impact. The Journal of Sexual Medicine, 13, 760-777. https://doi.org/10.1016/j.jsxm.2016.03.002 Eiser, J. R., Pligt, J. van der, Raw, M., \& Sutton, S. R. (1985). Trying to stop smoking: Effects of perceived addiction, attributions for failure, and expectancy of success. Journal of Behavioral Medicine, 8, 321-341. https://doi.org/10.1007/BF00848367 
Exline, J. J., Yali, A. M., \& Sanderson, W. C. (2000). Guilt, discord, and alienation: The role of religious strain in depression and suicidality. Journal of Clinical Psychology, 56, 1481-1496.

Fernandez, D. P., Tee, E. Y. J., \& Fernandez, E. F. (2017). Do Cyber Pornography Use Inventory-9 scores reflect actual compulsivity in internet pornography use? Exploring the role of abstinence effort. Sexual Addiction \& Compulsivity, 24, 156-179. https://doi.org/10.1080/10720162.2017.13 44166

Fisher, W. A., \& Barak, A. (2001). Internet pornography: A social psychological perspective on internet sexuality. The Journal of Sex Research, 38, 312-323. https://doi.org/10.1080/002244901095521 02

Foubert, J. D. (2016). How Pornography Harms: Today's Research, Scholarly Perspectives, and Real Life Stories. Taylor \& Francis.

Gola, M., Lewczuk, K., \& Skorko, M. (2016). What matters: Quantity or quality of pornography use? Psychological and behavioral factors of seeking treatment for problematic pornography use. The Journal of Sexual Medicine, 13, 815-824. https://doi.org/10.1016/j.jsxm.2016.02.169

Grubbs, J. B., Exline, J. J., Pargament, K. I., Hook, J. N., \& Carlisle, R. D. (2015).

Transgression as addiction: Religiosity and moral disapproval as predictors of perceived addiction to pornography. Archives of Sexual Behavior, 44, 125-136. https://doi.org/10.1007/s10508-013-0257-z

Grubbs, J. B., Exline, J. J., Pargament, K. I., Volk, F., \& Lindberg, M. J. (2017). Internet pornography use, perceived addiction, and religious/spiritual struggles. Archives of Sexual Behavior, 46, 1733-1745. https://doi.org/10.1007/s10508-016-0772-9
Grubbs, J. B., \& Perry, S. L. (2018). Moral incongruence and pornography use: A critical review and integration. The Journal of Sex Research. https://doi.org/10.1080/00224499.2018.14 27204

Grubbs, J. B., Stauner, N., Exline, J. J., Pargament, K. I., \& Lindberg, M. J. (2015). Perceived addiction to Internet pornography and psychological distress: Examining relationships concurrently and over time. Psychology of Addictive Behaviors, 29, 1056.

Grubbs, J. B., Volk, F., Exline, J. J., \& Pargament, K. I. (2015). Internet pornography use: Perceived addiction, psychological distress, and the validation of a brief measure. Journal of Sex \& Marital Therapy, 41, 83-106. https://doi.org/10.1080/0092623X.2013.84 2192

Grubbs, J. B., Wilt, J. A., Exline, J. J., Pargament, K. I., \& Kraus, S. W. (2017). Moral disapproval and perceived addiction to internet pornography: A longitudinal examination. Addiction, n/a-n/a. https://doi.org/10.1111/add.14007

Hughes, M. E., Waite, L. J., Hawkley, L. C., \& Cacioppo, J. T. (2004). A short scale for measuring loneliness in large surveys: Results from two population-based studies. Research on Aging, 26, 655-672.

Kalman, T. P. (2008). Clinical encounters with Internet pornography. Journal of the American Academy of Psychoanalysis and Dynamic Psychiatry, 36, 593-618.

Kerr, N. L. (1998). HARKing: Hypothesizing after the results are known. Personality and Social Psychology Review, 2, 196-217.

Kraus, S. W., Martino, S., \& Potenza, M. N. (2016). Clinical characteristics of men interested in seeking treatment for use of pornography. Journal of Behavioral 
Addictions, 5, 169-178. https://doi.org/10.1556/2006.5.2016.036

Kraus, S. W., Voon, V., \& Potenza, M. N. (2016).

Should compulsive sexual behavior be considered an addiction? Addiction, 111, 2097-2106.

https://doi.org/10.1111/add.13297

Leonhardt, N. D., Willoughby, B. J., \& Young-

Petersen, B. (2017). Damaged goods:

Perception of pornography addiction as a mediator between religiosity and relationship anxiety surrounding pornography use. The Journal of Sex Research, 0, 1-12. https://doi.org/10.1080/00224499.2017.12 95013

Ley, D. J., Prause, N., \& Finn, P. (2014). The emperor has no clothes: A review of the 'pornography addiction' model. Current Sexual Health Reports, 6, 94-105. https://doi.org/10.1007/s11930-014-0016-8

Mitchell, K. J., Becker-Blease, K. A., \& Finkelhor, D. (2005). Inventory of Problematic Internet Experiences Encountered in Clinical Practice. Professional Psychology: Research and Practice, 36, 498-509. https://doi.org/10.1037/07357028.36.5.498

Morelli, M., Bianchi, D., Baiocco, R., Pezzuti, L., \& Chirumbolo, A. (2017). Sexting behaviors and cyber pornography addiction among adolescents: The moderating role of alcohol consumption. Sexuality Research and Social Policy, 14, 113-121. https://doi.org/10.1007/s13178016-0234-0

NoFap.com. (2017). Retrieved October 20, 2017, from https://www.nofap.com/

Okoli, C. T. C., Richardson, C. G., Ratner, P. A., \& Johnson, J. L. (2009). Non-smoking youths' "perceived" addiction to tobacco is associated with their susceptibility to future smoking. Addictive Behaviors, 34, 1010-1016. https://doi.org/10.1016/j.addbeh.2009.06.0 10

Perry, S. L. (2015). Pornography consumption as a threat to religious socialization. Sociology of Religion, 76, 436-458. https://doi.org/10.1093/socrel/srv043

Perry, S. L. (2017). Not practicing what you preach: Religion and incongruence between pornography beliefs and usage. The Journal of Sex Research, 0, 1-12. https://doi.org/10.1080/00224499.2017.13 33569

Price, J., Patterson, R., Regnerus, M., \& Walley, J. (2016). How much more $\mathrm{xxx}$ is generation $\mathrm{x}$ consuming? Evidence of changing attitudes and behaviors related to pornography since 1973. The Journal of Sex Research, 53, 12-20. https://doi.org/10.1080/00224499.2014.10 03773

Rasmussen, K. R. (2016). A Historical and Empirical Review of Pornography and Romantic Relationships: Implications for Family Researchers: Pornography and Romantic Relationships. Journal of Family Theory \& Review, 8, 173-191. https://doi.org/10.1111/jftr.12141

Rasmussen, K. R., \& Bierman, A. (2016). How does religious attendance shape trajectories of pornography use across adolescence? Journal of Adolescence, 49, 191-203.

Rasmussen, K. R., Grubbs, J. B., Pargament, K. I., \& Exline, J. J. (2017). Social Desirability Bias in Pornography-Related Self-Reports: The Role of Religion. The Journal of Sex Research, 1-14. https://doi.org/10.1080/00224499.2017.13 99196

Reboot Nation. (2017). Retrieved October 20, 2017, from http://www.rebootnation.org/

Regnerus, M., Gordon, D., \& Price, J. (2016). Documenting pornography use in America: a comparative analysis of 
methodological approaches. The Journal of Sex Research, 53, 873-881.

Revelle, W. (2014). psych: Procedures for psychological, psychometric, and personality research. Northwestern University, Evanston, Illinois, 165.

Reynolds, W. M. (1982). Development of reliable and valid short forms of the MarloweCrowne Social Desirability Scale. Journal of Clinical Psychology, 38, 119-125.

Rissel, C., Richters, J., Visser, R. O. de, McKee, A., Yeung, A., \& Caruana, T. (2017). A profile of pornography users in australia: Findings from the second australian study of health and relationships. The Journal of Sex Research, 54, 227-240. https://doi.org/10.1080/00224499.2016.11 91597

Shapiro, D. N., Chandler, J., \& Mueller, P. A. (2013). Using Mechanical Turk to study clinical populations. Clinical Psychological Science, 1, 213-220.

Short, M. B., Black, L., Smith, A. H., Wetterneck, C. T., \& Wells, D. E. (2011). A review of internet pornography use research: Methodology and content from the past 10 years. Cyberpsychology, Behavior, and Social Networking, 15, 13-23. https://doi.org/10.1089/cyber.2010.0477

Short, M. B., Wetterneck, C. T., Bistricky, S. L., Shutter, T., \& Chase, T. E. (2016). Clinicians' beliefs, observations, and treatment effectiveness regarding clients' sexual addiction and internet pornography use. Community Mental Health Journal, 52, 1070-1081. https://doi.org/10.1007/s10597-016-0034-2

Spellman, B., Gilbert, E., \& Corker, K. S. (2017). Open Science: What, Why, and How. PsyArXiv. https://doi.org/10.17605/OSF.IO/AK6JR

Struthers, W. M. (2009). Wired for intimacy: How pornography hijacks the male brain. Downers Grove, IL: InterVarsity Press.
Tangney, J. P., Baumeister, R. F., \& Boone, A. L. (2004). High self-control predicts good adjustment, less pathology, better grades, and interpersonal success. Journal of Personality, 72, 271-324.

Twohig, M. P., \& Crosby, J. M. (2010). Acceptance and commitment therapy as a treatment for problematic internet pornography viewing. Behavior Therapy, 41, 285-295.

https://doi.org/10.1016/j.beth.2009.06.002

Volk, F., Thomas, J., Sosin, L., Jacob, V., \& Moen, C. (2016). Religiosity, developmental context, and sexual shame in pornography users: A serial mediation model. Sexual Addiction \& Compulsivity, 23, 244-259. https://doi.org/10.1080/10720162.2016.11 51391

Wilson, G. (2014). Your brain on porn: Internet pornography and the emerging science of addiction. Commonwealth Publishing Richmond, VA.

Wilt, J. A., Cooper, E. B., Grubbs, J. B., Exline, J. J., \& Pargament, K. I. (2016). Associations of perceived addiction to internet pornography with religious/spiritual and psychological functioning. Sexual Addiction \& Compulsivity, 23, 260-278. https://doi.org/10.1080/10720162.2016.11 40604

Wright, P. J. (2012). A longitudinal analysis of U.S. adults' pornography exposure. Journal of Media Psychology, 24, 67-76. https://doi.org/10.1027/18641105/a000063

Wright, P. J. (2013). U.S. males and pornography, 1973-2010: Consumption, predictors, correlates. The Journal of Sex Research, $50,60-71$. https://doi.org/10.1080/00224499.2011.62 8132

Yoder, V. C., Virden III, T. B., \& Amin, K. (2005). Internet pornography and 
loneliness: An association? Sexual

Addiction \& Compulsivity, 12, 19-44.

Your Brain On Porn. (2017). Retrieved October

20, 2017, from

https://www.yourbrainonporn.com/ 
Table 1

Descriptive Statistics for Included Measures

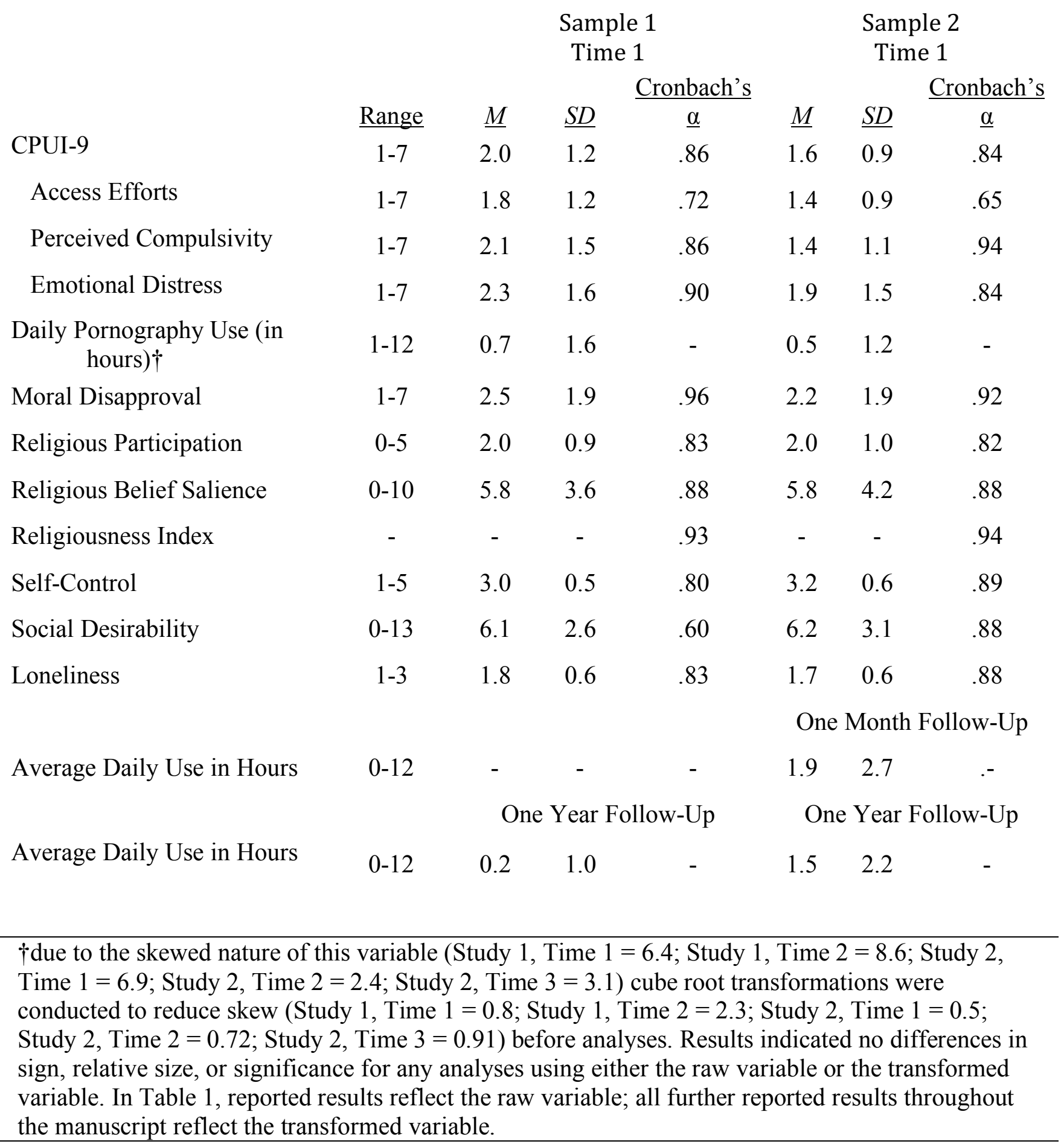


Table 2

Binary Logistic Regression Predicting Pornography Exposure

\begin{tabular}{|c|c|c|c|c|c|c|c|c|}
\hline & \multicolumn{4}{|c|}{ Sample 1} & \multicolumn{4}{|c|}{ Sample 2} \\
\hline & $\underline{B}(\mathrm{SE})$ & Wald (df) & $\frac{p \text {-value }}{\text { (Holmt) }}$ & $\underline{\mathrm{OR}}[95 \% \mathrm{Cl}]$ & $\underline{B}(\mathrm{SE})$ & $\underline{\text { Wald (df) }}$ & $\frac{p \text {-value }}{\text { (Holmt) }}$ & OR [95\% Cl] \\
\hline Male Gender & $2.34(.08)$ & $806.33(1)$ & $.000(.000)$ & $10.43[8.87,12.26]$ & $1.94(0.16)$ & $145.66(1)$ & $.000(.000)$ & $6.95[5.07,9.53]$ \\
\hline Self-Control & $-0.44(.09)$ & $23.08(1)$ & $.000(.000)$ & $0.64[0.54,0.77]$ & $-0.82(0.14)$ & $32.98(1)$ & $.000(.000)$ & $0.44[0.33,0.58]$ \\
\hline $\begin{array}{l}\text { Social } \\
\text { Desirability }\end{array}$ & $0.00(.02)$ & $0.01(1)$ & $.92(1.000)$ & $1.00[0.97,1.04]$ & $0.02(0.03)$ & $0.30(1)$ & $.916(.587)$ & $1.02[0.96,1.07]$ \\
\hline Loneliness & $0.43(.07)$ & $38.19(1)$ & $.000(.000)$ & $1.54[1.34,1.76]$ & $0.26(0.12)$ & $4.45(1)$ & $.035(.070)$ & $1.3[1.02,1.66]$ \\
\hline Religiousness & $-0.54(.05)$ & $140.75(1)$ & $.000(.000)$ & $0.59[0.54,0.64]$ & $-0.58(0.1)$ & $36.82(1)$ & $.000(.000)$ & $0.56[0.47,0.68]$ \\
\hline
\end{tabular}

†Holm adjusted test statistic in parentheses

OR = Odds Ratio 
Table 3

Correlations of Included Variables

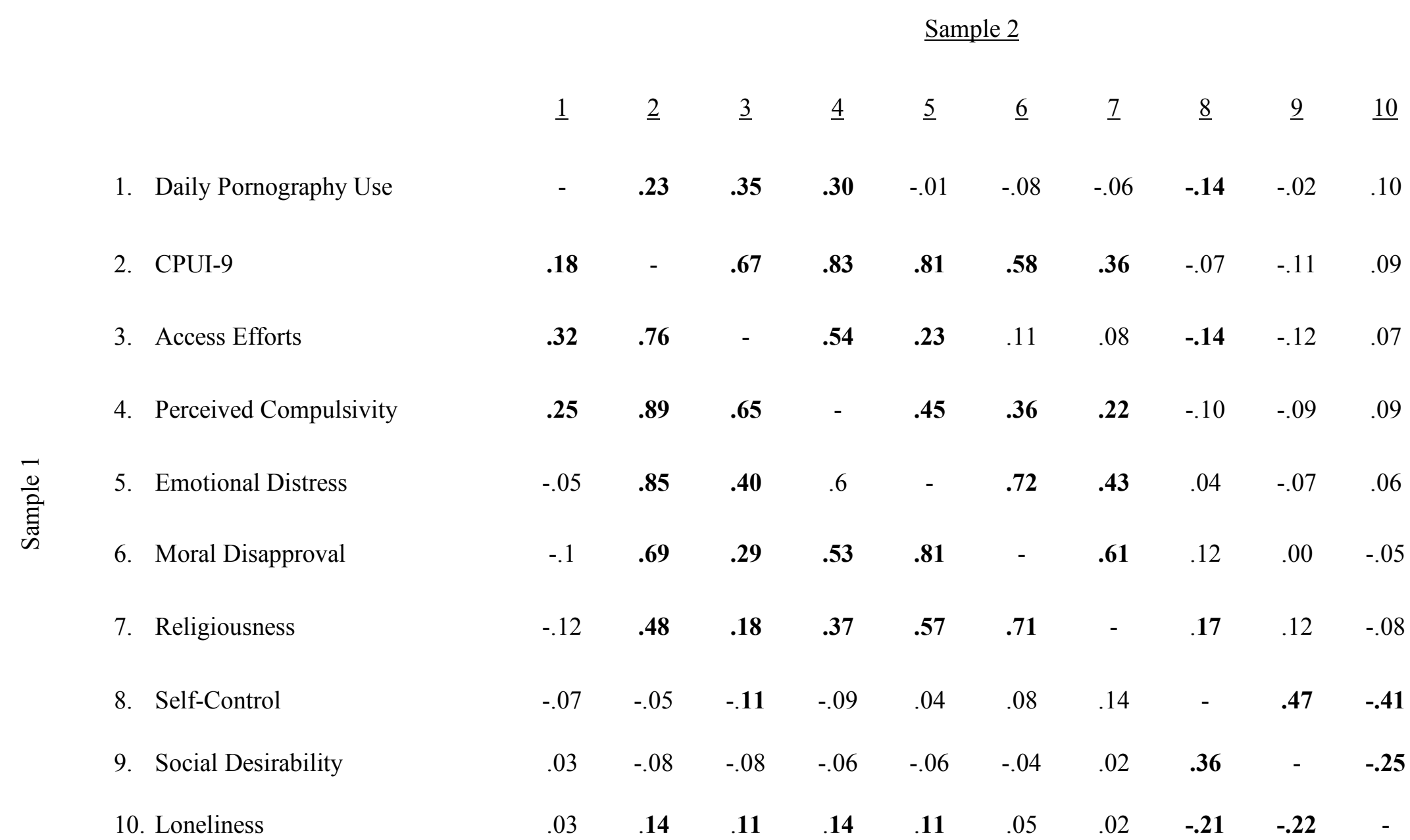

Correlations (in boldface) in Sample 1 (below the diagonal) with greater absolute value than $r=|.10|$ and correlations in Sample 2 (above the diagonal) with greater absolute value than $r=|.13|$ significant at $p<.005$ with Holm-adjusted test statistics. 
Table 4

Multiple Regression Predicting Average Daily Use Cross-Sectionally

Sample 1

Sample 2

\begin{tabular}{|c|c|c|c|c|}
\hline & $\underline{B}(95 \% \mathrm{Cl})$ & p-value (Holm) & $\underline{B}(95 \% \mathrm{Cl})$ & p-value (Holm) \\
\hline Male Gender & $.086(0.001,0.17)$ & $.047(.141)$ & $.167(0.111,0.223)$ & $.000(.000)$ \\
\hline Self-Control & $-.017(-0.108,0.073)$ & $.705(1.00)$ & $-.056(-0.107,-0.006)$ & $.028(.156)$ \\
\hline Social Desirability & $.02(0.004,0.037)$ & $.017(.085)$ & $.037(-0.007,0.081)$ & $.099(.297)$ \\
\hline Loneliness & $.012(-0.052,0.077)$ & $.708(1.00)$ & $.011(0.001,0.021)$ & $.026(.156)$ \\
\hline Religiousness & $-.068(-0.131,-0.006)$ & $.031(.124)$ & $-.001(-0.045,0.043)$ & $.959(.959)$ \\
\hline Moral & $-.054(-0.088,-0.02)$ & $.002(.012)$ & $-.024(-0.047,-0.001)$ & $.040(.160)$ \\
\hline Access Efforts & $.176(0.135,0.216)$ & $.000(.000)$ & $.109(0.072,0.146)$ & $.000(.000)$ \\
\hline Perceived Compulsivity & $.139(0.102,0.177)$ & $.000(.000)$ & $.072(0.04,0.103)$ & $.000(.000)$ \\
\hline Emotional Distress & $-.065(-0.101,-0.03)$ & $.000(.000)$ & $-.022(-0.049,0.005)$ & $.104(.297)$ \\
\hline$R^{2}$ & \multicolumn{2}{|c|}{.189} & \multicolumn{2}{|c|}{.218} \\
\hline$f^{2}$ & \multicolumn{2}{|c|}{.233} & \multicolumn{2}{|c|}{.279} \\
\hline$F$ for $R^{2}$ & \multicolumn{2}{|c|}{$38.99^{\star \star}$} & \multicolumn{2}{|c|}{$23.82^{\star \star}$} \\
\hline
\end{tabular}


Table 5

Binary Logistic Regression Predicting Any Pornography Exposure Over Time

\begin{tabular}{|c|c|c|c|c|c|c|c|c|c|c|c|c|}
\hline & \multicolumn{4}{|c|}{$\begin{array}{c}\text { Sample } 1 \\
1 \text { year }\end{array}$} & \multicolumn{4}{|c|}{$\begin{array}{c}\text { Sample } 2 \\
1 \text { month }\end{array}$} & \multicolumn{4}{|c|}{$\begin{array}{c}\text { Sample } 2 \\
1 \text { year }\end{array}$} \\
\hline & $\begin{array}{c}B \\
(S E)\end{array}$ & $\begin{array}{l}\text { Wald } \\
\text { (df) }\end{array}$ & $\begin{array}{l}\text { p-value } \\
\text { (Holm†) }\end{array}$ & $\begin{array}{c}\text { OR } \\
{[95 \% \mathrm{Cl}]}\end{array}$ & B (SE) & $\begin{array}{l}\text { Wald } \\
\text { (df) }\end{array}$ & $\begin{array}{c}\text { p-value } \\
\text { (Holm) }\end{array}$ & $\begin{array}{c}\text { OR } \\
{[95 \% \mathrm{Cl}]}\end{array}$ & $\begin{array}{c}\mathrm{B} \\
(\mathrm{SE})\end{array}$ & $\begin{array}{l}\text { Wald } \\
\text { (df) }\end{array}$ & $\begin{array}{c}\text { p-value } \\
(\text { Holm })\end{array}$ & $\begin{array}{c}\text { OR } \\
{[95 \% \mathrm{Cl}]}\end{array}$ \\
\hline Male & $\begin{array}{l}1.199 \\
(.31)\end{array}$ & $\begin{array}{l}14.96 \\
(1)\end{array}$ & $\begin{array}{l}.000 \\
(.000)\end{array}$ & $\begin{array}{l}3.32 \\
{[1.81,6.09]}\end{array}$ & $\begin{array}{l}1.608 \\
(.248)\end{array}$ & $\begin{array}{l}41.98 \\
(1)\end{array}$ & $\begin{array}{l}.000 \\
(.000)\end{array}$ & $\begin{array}{l}5.00 \\
{[3.07,8.13]}\end{array}$ & $\begin{array}{l}1.587 \\
(.268)\end{array}$ & $\begin{array}{l}35.13 \\
(1)\end{array}$ & $\begin{array}{l}.000 \\
(.000)\end{array}$ & $\begin{array}{l}4.89 \\
{[2.89,8.26]}\end{array}$ \\
\hline $\begin{array}{l}\text { Self- } \\
\text { Control }\end{array}$ & $\begin{array}{l}-.201 \\
(.309)\end{array}$ & $\begin{array}{l}0.43 \\
(1)\end{array}$ & $\begin{array}{l}.514 \\
(1.00)\end{array}$ & $\begin{array}{l}0.82 \\
{[0.45,1.50]}\end{array}$ & $\begin{array}{l}-.524 \\
(.213)\end{array}$ & $\begin{array}{l}6.05 \\
(1)\end{array}$ & $\begin{array}{l}.014 \\
(.098)\end{array}$ & $\begin{array}{l}0.59 \\
{[0.39,0.90]}\end{array}$ & $\begin{array}{l}-.639 \\
(.222)\end{array}$ & $\begin{array}{l}8.30 \\
(1)\end{array}$ & $\begin{array}{l}.004 \\
(.032)\end{array}$ & $\begin{array}{l}0.53 \\
{[0.34,0.82]}\end{array}$ \\
\hline Lone. & $\begin{array}{l}-.038 \\
(.253)\end{array}$ & $\begin{array}{l}0.02 \\
(1)\end{array}$ & $\begin{array}{l}.881 \\
(1.00)\end{array}$ & $\begin{array}{l}0.96 \\
{[0.59,1.58]}\end{array}$ & $\begin{array}{l}-.124 \\
(.193)\end{array}$ & $\begin{array}{l}0.41 \\
(1)\end{array}$ & $\begin{array}{l}.521 \\
(1.000)\end{array}$ & $\begin{array}{l}0.88 \\
{[0.61,1.29]}\end{array}$ & $\begin{array}{l}.215 \\
(.206)\end{array}$ & $\begin{array}{l}1.09 \\
(1)\end{array}$ & $\begin{array}{l}.296 \\
(1.00)\end{array}$ & $\begin{array}{l}1.24 \\
{[0.83,1.86]}\end{array}$ \\
\hline Relig. & $\begin{array}{l}.031 \\
(.275)\end{array}$ & $\begin{array}{l}0.01 \\
(1)\end{array}$ & $\begin{array}{l}.912 \\
(1.00)\end{array}$ & $\begin{array}{l}1.03 \\
{[0.60,1.77]}\end{array}$ & $\begin{array}{l}-.392 \\
(.212)\end{array}$ & $\begin{array}{l}3.42 \\
(1)\end{array}$ & $\begin{array}{l}.064 \\
(.384)\end{array}$ & $\begin{array}{l}0.68 \\
{[.45,1.02]}\end{array}$ & $\begin{array}{l}-.103 \\
(.217)\end{array}$ & $\begin{array}{l}0.22 \\
(1)\end{array}$ & $\begin{array}{l}.636 \\
(1.00)\end{array}$ & $\begin{array}{l}0.90 \\
{[0.59,1.38]}\end{array}$ \\
\hline $\begin{array}{l}\text { Porn } \\
\text { Use }\end{array}$ & $\begin{array}{l}-.153 \\
(.353)\end{array}$ & $\begin{array}{l}0.19 \\
(1)\end{array}$ & $\begin{array}{l}.665 \\
(1.00)\end{array}$ & $\begin{array}{l}0.86 \\
{[0.43,1.72]}\end{array}$ & $\begin{array}{l}1.385 \\
(.327)\end{array}$ & $\begin{array}{l}17.98 \\
(1)\end{array}$ & $\begin{array}{l}.000 \\
(.000)\end{array}$ & $\begin{array}{l}4.00 \\
{[2.11,7.58]}\end{array}$ & $\begin{array}{l}1.243 \\
(.344)\end{array}$ & $\begin{array}{l}13.07 \\
(1)\end{array}$ & $\begin{array}{l}.000 \\
(.000)\end{array}$ & $\begin{array}{l}3.47 \\
{[1.77,6.80]}\end{array}$ \\
\hline Mor Dis & $\begin{array}{l}-.038 \\
(.124)\end{array}$ & $\begin{array}{l}0.09 \\
(1)\end{array}$ & $\begin{array}{l}.762 \\
(1.00)\end{array}$ & $\begin{array}{l}0.96 \\
{[.76,1.23]}\end{array}$ & $\begin{array}{l}-.058 \\
(.121)\end{array}$ & $\begin{array}{l}0.23 \\
(1)\end{array}$ & $\begin{array}{l}.630 \\
(1.000)\end{array}$ & $\begin{array}{l}0.94 \\
{[.74,1.20]}\end{array}$ & $\begin{array}{l}-.186 \\
(.130)\end{array}$ & $\begin{array}{l}2.03 \\
(1)\end{array}$ & $\begin{array}{l}.154 \\
(.924)\end{array}$ & $\begin{array}{l}0.83 \\
{[0.64,1.07]}\end{array}$ \\
\hline $\begin{array}{l}\text { Access } \\
\text { Efforts }\end{array}$ & $\begin{array}{l}-.216 \\
(.145)\end{array}$ & $\begin{array}{l}2.22 \\
(1)\end{array}$ & $\begin{array}{l}.136 \\
(1.00)\end{array}$ & $\begin{array}{l}0.81 \\
{[0.61,1.07]}\end{array}$ & $\begin{array}{l}.369 \\
(.202)\end{array}$ & $\begin{array}{l}3.33 \\
(1)\end{array}$ & $\begin{array}{l}.068 \\
(.384)\end{array}$ & $\begin{array}{l}1.45 \\
{[0.97,2.15]}\end{array}$ & $\begin{array}{l}.576 \\
(.243)\end{array}$ & $\begin{array}{l}5.62 \\
(1)\end{array}$ & $\begin{array}{l}.018 \\
(.126)\end{array}$ & $\begin{array}{l}1.78 \\
{[1.11,2.86]}\end{array}$ \\
\hline $\begin{array}{l}\text { Perc. } \\
\text { Comp. }\end{array}$ & $\begin{array}{l}.61 \\
(.14)\end{array}$ & $\begin{array}{l}19.01 \\
(1)\end{array}$ & $\begin{array}{l}.000 \\
(.000)\end{array}$ & $\begin{array}{l}1.84 \\
{[1.40,2.42]}\end{array}$ & $\begin{array}{l}.100 \\
(.177)\end{array}$ & $\begin{array}{l}0.32 \\
(1)\end{array}$ & $\begin{array}{l}.574 \\
(1.000)\end{array}$ & $\begin{array}{l}1.11 \\
{[0.78,1.56]}\end{array}$ & $\begin{array}{l}.144 \\
(.183)\end{array}$ & $\begin{array}{l}0.62 \\
(1)\end{array}$ & $\begin{array}{l}.432 \\
(1.00)\end{array}$ & $\begin{array}{l}1.15 \\
{[0.81,1.65]}\end{array}$ \\
\hline $\begin{array}{l}\text { Emotion } \\
\text { Distress }\end{array}$ & $\begin{array}{l}-.123 \\
(.125)\end{array}$ & $\begin{array}{l}0.97 \\
(1)\end{array}$ & $\begin{array}{l}.325 \\
(1.00) \\
\end{array}$ & $\begin{array}{l}0.88 \\
{[0.69,1.13]}\end{array}$ & $\begin{array}{l}.032 \\
(.14)\end{array}$ & $\begin{array}{l}0.05 \\
(1)\end{array}$ & $\begin{array}{l}.822 \\
(1.000)\end{array}$ & $\begin{array}{l}1.03 \\
{[0.78,1.36]}\end{array}$ & $\begin{array}{l}.096 \\
(.156)\end{array}$ & $\begin{array}{l}0.38 \\
(1)\end{array}$ & $\begin{array}{l}.540 \\
(1.00) \\
\end{array}$ & $\begin{array}{l}1.10 \\
{[0.81,1.50]}\end{array}$ \\
\hline
\end{tabular}

†Holm adjusted test statistic in parentheses

OR = Odds Ratio; Lone = Loneliness; Relig = Religiousness; Mor Dis = Moral Disapproval; Perc. Comp. = Perceived Compulsivity, Em.

Di. = Emotional Distress 
Table 6

Multiple Regression Predicting Average Daily Porn Use in Hours Over Time

\begin{tabular}{|c|c|c|c|c|c|c|}
\hline & \multicolumn{2}{|c|}{$\frac{\text { Sample } 1}{\underline{1 \text { Year }}}$} & \multicolumn{2}{|c|}{$\frac{\text { Sample 2 }}{\underline{1 \text { Month }}}$} & \multicolumn{2}{|c|}{$\frac{\text { Sample } 2}{1 \text { Year }}$} \\
\hline & B $(95 \% C l)$ & p-value (Holm) & B $(95 \% \mathrm{Cl})$ & $\frac{p \text {-value }}{\text { (Holm) }}$ & B $(95 \%$ Cl) & p-value (Holm) \\
\hline Male Gender & $\begin{array}{c}.070 \\
(-.085, .225)\end{array}$ & $.371(1.00)$ & $.123(-.021, .267)$ & $.094(752)$ & $.056(-.075, .188)$ & $.401(1.00)$ \\
\hline Self-Control & $\begin{array}{c}-.087 \\
(-.239, .064)\end{array}$ & $.255(1.00)$ & $-.016(-.132, .099)$ & $.781(1.00)$ & $-.100(-.205, .005)$ & $.061(.366)$ \\
\hline Social Desirability & $\begin{array}{c}.017 \\
(-.013, .047)\end{array}$ & $.254(1.00)$ & $-.016(-.115, .084)$ & $.758(1.00)$ & $-.094(-.183,-.004)$ & $.040(.320)$ \\
\hline Loneliness & $\begin{array}{c}-.046 \\
(-.170, .078)\end{array}$ & $.463(1.00)$ & $.009(-.013, .031)$ & .435 (1.00) & $.036(.016, .056)$ & $.000(.000)$ \\
\hline Religiousness & $\begin{array}{c}.015 \\
(-.122, .151)\end{array}$ & $.834(1.00)$ & $-.064(-.174, .047)$ & $.256(1.00)$ & $-.041(-.149, .068)$ & $.459(1.00)$ \\
\hline Pornography Use & $\begin{array}{c}.260 \\
(.089, .431)\end{array}$ & $.003(.030)$ & $.410(.233, .588)$ & $.000(.000)$ & $.17(.006, .334)$ & $.042(.320)$ \\
\hline $\begin{array}{l}\text { Moral } \\
\text { Incongruence }\end{array}$ & $\begin{array}{c}-.022 \\
(-.079, .035)\end{array}$ & $.439(1.00)$ & $.019(-.048, .087)$ & .579 (1.00) & $-.006(-.067, .054)$ & $.832(1.00)$ \\
\hline Access Efforts & $\begin{array}{c}.042 \\
(-.028, .112)\end{array}$ & $.242(1.00)$ & $.074(-.003, .150)$ & $.060(.540)$ & $.140(.068, .213)$ & $.000(.001)$ \\
\hline $\begin{array}{l}\text { Perceived } \\
\text { Compulsivity }\end{array}$ & $\begin{array}{c}.039 \\
(-.025, .104)\end{array}$ & .229 (1.00) & $-.018(-.083, .047)$ & $.582(1.00)$ & $.018(-.045, .081)$ & $.576(1.00)$ \\
\hline $\begin{array}{l}\text { Emotional } \\
\text { Distress }\end{array}$ & $\begin{array}{c}.009 \\
(-.048, .067) \\
\end{array}$ & $.757(1.00)$ & $.005(-.080, .089)$ & $.911(1.00)$ & $.033(-.044, .111)$ & $.397(1.00)$ \\
\hline$R^{2}$ & \multicolumn{2}{|c|}{.165} & \multicolumn{2}{|l|}{.196} & \multicolumn{2}{|c|}{.279} \\
\hline$f^{2}$ & \multicolumn{2}{|c|}{.198} & \multicolumn{2}{|l|}{.244} & \multicolumn{2}{|c|}{.387} \\
\hline$F$ for $R^{2}$ & \multicolumn{2}{|c|}{$2.92^{\star \star}$} & \multicolumn{2}{|c|}{$4.89^{* *}$} & \multicolumn{2}{|c|}{$6.34^{\star *}$} \\
\hline
\end{tabular}

